\title{
OCCUPATIONAL SAFETY AND HEALTH HAZARDS OF APPAREL SECTOR: PERSPECTIVE OF NORTHERN PROVINCE EMPLOYEES OF SRI LANKA
}

\author{
THATSHAYINI. P. \& RAJINI. P.A.D. \\ Department of Building Economics, \\ University of Moratuwa, Sri Lanka \\ pthatsha@gmail.com,dame_uom@yahoo.com
}

\begin{abstract}
Occupational Safety and Health (OSH) is an important aspect which allows an organisation to systematically manage the safety and health of the workers in a workplace. Adoption of OSH in a work environment therefore helps for the promotion and maintenance of the highest degree of physical, mental and social wellbeing in all occupations. Literature reveals that the apparel sector's working environment is mostly associated with different kinds of workers, machinery and management teams and therefore, it should be safe and free from safety and health risks and hazards. Although there is a growing concern on OSH hazards, a lack of attention has received for researches on OSH in Sri Lankan context. Further, researches conducted on OSH in Northern in Sri Lanka are hardly found. Hence, the aim of this research is to investigate the level of exposure of employees working in apparel manufacturing organisations in Northern Province of Sri Lanka to different OSH hazards.

A comprehensive literature review identified 31number of OSH hazards of apparel sector in the global and local contexts and the levels of exposure of the employees to those hazards were identified through a questionnaire survey. The data were collected from 76 number of employees working in eight different apparel manufacturing organisations in Northern Province of Sri Lanka. The collected data were analysed using RII (Relative Importance Index) method. As the study revealed, the hazards to which the apparel manufacturing employees in Northern Province of Sri Lanka are mostly exposed to are "excessive noise", "repetitive nature of works", "stress", "excessive exposure to cotton dust" and "taking imbalance diet" under physical, ergonomic, psychological, chemical and biological hazard categories respectively.
\end{abstract}

Keywords: Occupational Safety and Health (OSH), Hazards, Apparel Sector, Northern Province, Sri Lanka. 


\section{Introduction}

According to Industrial Accident Prevention Association (2007), the term OSH is defined as the maintenance of a work environment that is relatively free from actual or potential hazards that can injure employees. Lack of clear approaches on how to manage OSH will led to a rise in work related injuries (Motbainor, Kumie, \& Melkamu, 2007). Therefore, the proper implementation of OSH at workplaces is equally important to both individuals and organisations and also indirectly to countries (Legesse, 2016). The concept of an OSH management system has become increasingly popular among different stakeholders of OSH over the years (European Agency for Safety and Health at Work, 2012). According to Ahmed and Raihan (2014), the current working environment of apparel sector is not congenial to ensure good health. As mentioned by Sobuj (2011), apparel manufacturing organisations like other industrial processes involve hazardous work (Sobuj, 2011). Industrial production, dyeing, washing and others processes result in cotton dust and chemical reagents which is harmful for humans. Further, poor ergonomic design and other OSH hazards lead to different OSH issues even the death (Talapatra \& Rahman, 2016). However, Sri Lanka is considered to be one of the most vulnerable countries and is ranked at a low level for OSH performance due to lack of improvement measures (De Silva \& Wimalaratne, 2012). Further, a little number of researches have been conducted in the area of OSH in Sri Lankan context, especially focusing the Northern Province. Hence, this paper presents the findings of a study carried out to investigate the OSH hazards faced by apparel manufacturing employees in Northern Province of Sri Lanka.

The paper starts with a review of literature related to $\mathrm{OSH}$, its importance and $\mathrm{OSH}$ hazards in a workplace. Secondly, it discusses the method used to achieve the aim of this research. Next, the findings of the study are discussed and finally, the conclusions are presented.

\section{Literature Review}

\section{An overview of Occupational Safety and Health}

Occupational Safety and Health (OSH) is a multi-disciplinary concept that concentrates on the promotion of safety, health and welfare of people engaged in work or employment (Bhagawati, 2015). According to Alli (2008), OSH is generally defined as the science of the anticipation, recognition, evaluation and control of hazards arising in or from the workplace that could impair the health and well-being of workers and taking into account the possible impacts on the surrounding communities and the general environment. As per International Labour Organisation (2010), OSH is a discipline with a broad scope involving many specialized fields. 
In its broadest sense, it should aim at the promotion and maintenance of the highest degree of physical, mental and social well-being of workers in all occupations; the prevention among workers of adverse effects on health caused by their working conditions; the protection of workers in their employment from risks resulting from factors adverse to health; the placing and maintenance of workers in an occupational environment adapted to physical and mental needs and the adaptation of work to humans.

OSH in workplace is one of the core concepts considered by all kinds of organisations to be responsible for protecting and optimizing the functionality of human resource (Eddie \& Fang, 2004). It helps to control the dangers which are emerging from physical, chemical, and other work environment perils so as to set up and keep up a safe and sound workplace (Mohibullah, et al., 2018). Moreover, as Amponsah and Dartey (2011) described, OSH captures the mental, emotional and physical well-being of the worker in relation to the conduct of the work and as a result, marks an essential subject of interest impacting positively on the achievement of organisational goals. Therefore, OSH management system helps to achieve the effective quality management, protection of the working person and the environment (Tawiah \& Mensah, 2016). Furthermore, according to Khan, et al. (2016), OSH can also reduce employee injury and illness related costs, including medical care, sick leave and disability benefit costs, etc. If the organisations can prevent occupational health hazards, it can ensure the quality works done by the healthy workers with their efficiency and satisfaction. More workers will be encouraged to gain their skill in complex and challenging works when they will find assurance of healthy environment and health care provisions.

\section{Importance of OSH in Apparel Sector}

According to Saravanan (2011), the apparel industry is usually accepted as a safe place for working compared to other industries. However, as Legesse (2016) pointed out, the boom in the apparel manufacturing industry in developing countries brings risks associated with the workplaces. Some of these risks is typically high paced, demanding, involving relatively complex machineries with conveyors covering large areas and with high rate of human intervention and manual handling. As per, Sealetsa and Thatcher (2011), the workers' health related risk factors associated with the apparel industry are mostly occurred because of highly repetitive work in work postures. Further, as Sharif, et al. (2015) mentioned, OHS is directly relating to the workers of the garment factories as they are staying in the factories and in large 
numbers. And the workers are mostly affected for the incidents as they are mostly illiterate, not aware, not educated and not well trained to prevent the incidents and to rescue themselves from the incidents.

Numerous problems that have to be faced by the workers in apparels manufacturing industry make them injured day by day (Talapatra \& Rahman, 2016). Hazards in the apparel industry include accident hazards, such as burns and puncture wounds, physical hazards, such as heat and noise, chemical hazards, such as allergies, ergonomic hazards posed by poor posture, biological hazards from poor nutrition, and psychosocial ones that result from abuse on the part of supervisors and a depressing work environment. All of these are inter-related, and can affect both productivity in general and the individual health of the worker (Chaturvedi \& Kumar, 2015). According to International labour organization (2014), OSH promotion in worker intensive manufacturing sector is very important to maintain the highest degree of physical, mental and social well-being of workers in all occupations, the prevention of workers from adverse effects on health caused by their working circumstances, the protection of workers in their employment from risks resulting from factors adverse to health, the placing and maintenance of workers in an occupational environment adapted to physical and mental needs, the adaptation of work to humans.

\section{OSH Hazards of Apparel Manufacturing Organisations}

The OSH condition of the workers belonged to the apparel manufacturing industry is getting more critical and complicated gradually (Sobuj, 2011). In this industry, the major risks generally do not arise from direct dangerous hazards, instead, the real risk is hidden in indirect hazards that affect over time due to repetitive tasks (Saravanan, 2011). Therefore, it is necessary for employers and workers to be aware of the hazards associated with apparel manufacturing and take precautions to guard against workrelated illnesses and injuries (Sobuj, 2011). Thus, the identification of the OSH in apparel manufacturing industry is crucial for a better understanding of OSH practices.

By conducting an in-depth review of the literature, a total of thirty-one (31) OSH hazards could be identified from sixteen (16) literature sources on OSH hazards in apparel manufacturing industry. The identified OSH hazards with the respective authors have been shown in Table 1. All the OSH issues have been identified and classified as per the classification of International Labour Organisation. International Labour Organisation (2001) has categorised OSH hazards under five specific categories as 'physical hazards', 'ergonomic hazards', 'psychological hazards', 'chemical hazards', and 'biological hazards'. 
Table 1: OSH hazards of apparel manufacturing organisations

OSH issues in apparel sector

Reference Source

$\begin{array}{llllllllllllllll}1 & 2 & 3 & 4 & 5 & 6 & 7 & 8 & 9 & 10 & 11 & 12 & 13 & 14 & 15 & 16\end{array}$

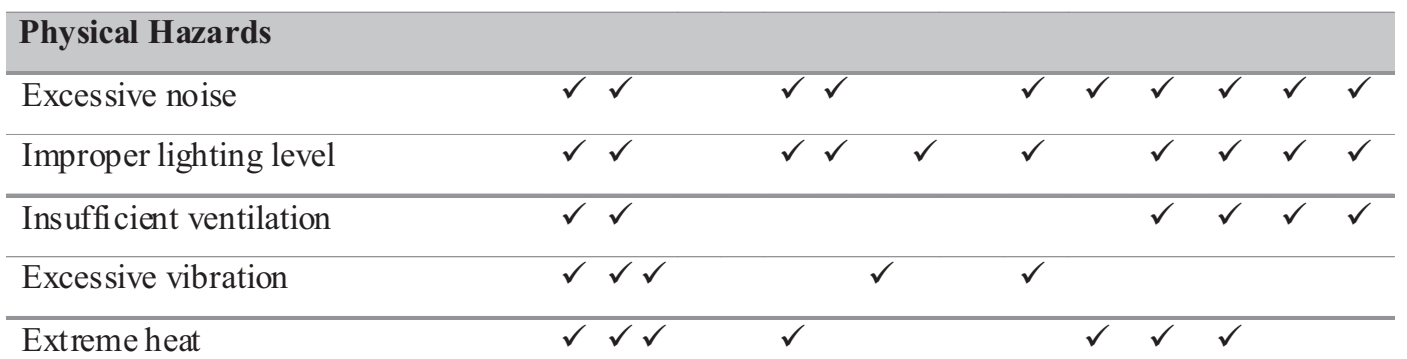

Poor air quality

Untidy working environment

Blockage in exit ways

(Especially in case of fire)

Absence of health facilities

(Pure drinking water, separate

washroom facilities)

\section{Ergonomic Hazards}

Poor ergonomic design of

workstations and work condition

(E.g. Uncomfortable seating

arrangements)

Badly designed machineries

Repetitive nature of works

Awkward postures

Lifting problems

Prolonged working hours

Manually operated machines

Inadequate circulation spaces

Lack of shifting and rotation system

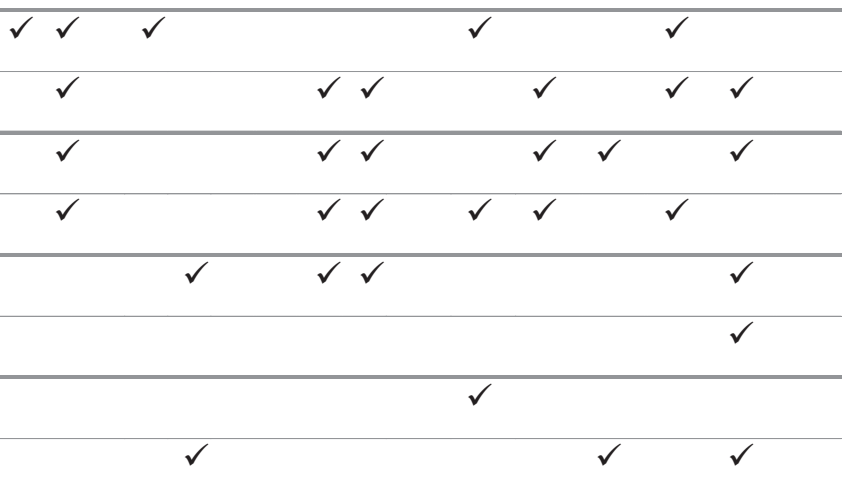

Psychological Hazards

Stress

Strain

Excessive physical workload 


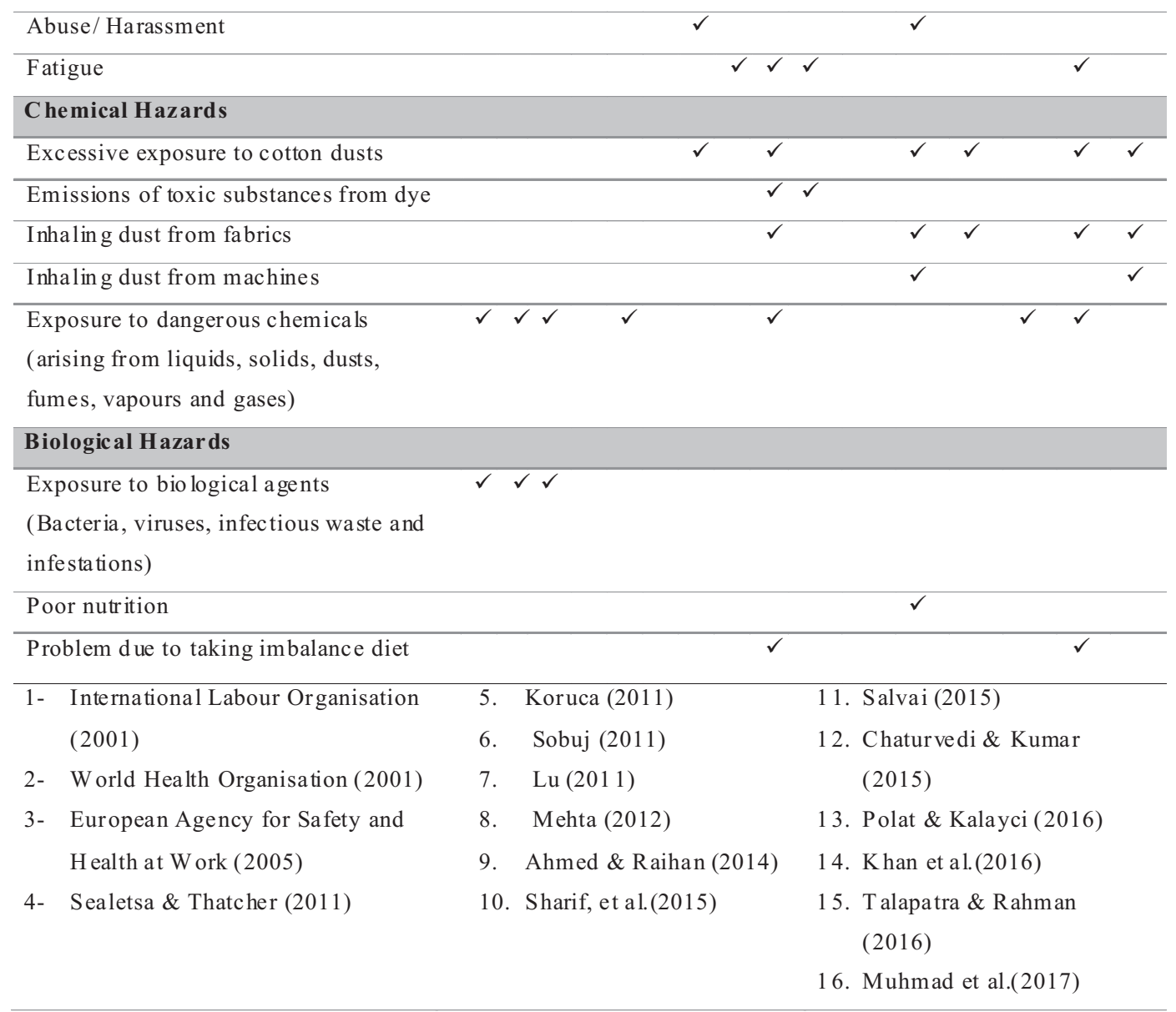

\section{Physical Hazards}

As Talapatra and Rahman (2016) mentioned, mostly common physical hazards of the production floor include exposure to sound, exposure to excessive temperature, vibration and unclean working environment in the factory. Further, as per Chaturvedi and Kumar (2015), the work safety, lighting, ventilation, cleanliness, disposal of wastes and effluents related aspects have not been given adequate attention in many garment factories in developing countries. Garment workers in Bangladesh have to work from dawn to dusk in a confined environment where proper ventilation of air is absent being a serious OSH physical hazard (Ahmed \& Raihan (2014). According to Mehta (2012), when numbers of sewing machines are compounded, it makes the environment noisy for the workers. All these problems unveil the dirty and hazardous working environment in the garment industry. Exposure to high noise levels has been known to damage the eardrum and cause hearing loss in the long run (Talapatra \& Rahman, 2016). The improper selection of lighting fixtures and their placements 
further contributes to neural problems. Poor housekeeping not only creates an accident hazard because of boxes, thread, trimmings and other combustible materials lying around the shop floor, but also can cause respiratory problems because of dust when combined with poor ventilation and the poor quality of masks (Chaturvedi \& Kumar, 2015). In addition, lack of working knowledge and safe drinking water were also mentioned as physical health hazards (Muhmad, et al., 2017).

\section{Ergonomic Hazard}

Most of the apparel production floors do not have ergonomically designed working conditions, due to which, the workers suffer from back pain, loose their eyesight and face numerous other problems (Talapatra \& Rahman, 2016). Heavy workloads and ergonomically inadequate working conditions can negatively influence health of the workers since the tasks in apparel industry include repetitive motions (Polat \& Kalayci, 2016). The monotonous work lead to increased worker fatigue due to continuous handling of loads, prolonged standing, repetitive movement of both hands and wrists and awkward postures. Further, the work of sewing machine operators often require them to adopt awkward work postures for long periods of time while executing high numbers of unvaried tasks which require both speed and repetition (Laville, 1985). Wrong working posture is also another reason because of which, apparel workers suffer from a number of health hazards (Mahmud,et al., 2017). Standardised workstations (Sealetsa \& Thatcher, 2011), the repetitive nature of the work and the poor awkward work postures adopted by workers (Sealetsa \& Thatcher, 2011; Chaturvedi \& Kumar, 2015); often lead to one or the other form of musculoskeletal disorders, which is a most common work related problem (Mehta, 2012). It affects the body muscles, joints, tendons, ligaments, bones and nerves. Further, most of the health problems that the garment workers suffered arose from the occupational hazards including long working hours, absence of leave facilities, congested and overcrowded working conditions, absence of health facilities and safety measures, absence of staff amenities, lack of safe drinking water, etc. (Bheda, 2004)

\section{Psychological Hazards}

As per European Agency for Safety and Health at Work (2005), the increase in psychosocial problems and illnesses is posing a new challenge to health and safety at work and is compromising moves to improve well-being at work. Stress, depression, nervousness, violence at work, harassment and pressure are considered as emerging illness in workplaces and obviously these illness creates problems associated with 
health at work (European Agency fro Safety and Health at Work, 2005). According to the International Labour Organisation (2010) and, Ahmed and Raihan (2014), increased mental workload may represent a source of psychological problems. As per Jana (2008), repetitive nature of work also negatively affect towards the psychosocial health of the workers. Moreover, as per Chaturvedi and Kumar (2015), psychosocial problems also arise due to the frustration occurred from the monotonous nature of the work, the risks involved, long working hours, lack of recognition for their work, lack of job satisfaction, daily abuse by supervisors, due to the absence of welfare activities, and tensions at the home and at the workplace. Further, reproductive health problems can also be occurred in apparel workplaces due to overwork, uncongenial working conditions, and wide-ranging labour law violations (Sharif, Islam, \& Kabir, 2015). In addition to that, pressure of higher productivity and quality of work, time pressure and hectic jobs impact on growing psychological workload and stress among the workforce (World Health Organisation, 1995).

\section{Chemical Hazards}

According to the Drusilla and Deardorff (2011), hazardous conditions of work range from the exposure to lint dust in an apparel factory to exposure to toxic chemicals in the recycling of electronic waste. Ahmed and Raihan (2014), mentioned that the female workers in the garment sector mainly stitch up the fabrics and therefore, they have to inhale dust of fabric causing health hazards and ultimately suffer from the diseases like asthma, respiratory problems, breathing problems, conjunctivitis and visual discomfort. Moreover, exposure to cotton dust and other particles leads to respiratory disorders among the apparel workers. And dust from the machines make the workers weak and also reduce the efficiency of the workers (Talapatra \& Rahman, 2016). Dust fibres mainly produced from cutting and sewing sections of garment industries can be seen on worktables, lamps and even workers hair. The smallest of these fibres are breathed by the workers and cause a variety of respiratory problems over the long term (Chaturvedi \& Kumar, 2015). In apparel sector, toxic chemicals being used during bleaching, dyeing, and printing and finishing processes. Due to the usage of chemicals accidents and diseases may arise (Lu, 2011). According to Sharif (2015), dye is a toxic substance emitted from coloured cloth, spreads in the workroom. As a result, many workers suffer from constant fatigue, headaches, anaemia, fever, chest, stomach, eye and ear pain, cough and cold, diarrhoea, dysentery, urinary tract infection. Further, Talapatra and Rahman (2016) explained that in the production line there creates micro cotton dust that causes cough, nasal problem and finally attack the lung. The cotton dust can cause an ultimate problem of the lung like lung cancer. Furthermore, dust and chemical particles also cause some health complications 
among the female workers of garment industry (Mahmud, et al., 2017). Finally, Mehta (2012) also showed that in the washing section, the workers are exposed to chemicals, particularly bleaches and detergents and are not aware of their health hazards leading to skin allergies.

\section{Biological Hazards}

According to Occupational Safety and Health Council (2003), biological hazards refer to organisms or organic matters produced by the organisms that are harmful to human health. These include parasites, viruses, bacteria, fungi and protein. Chaturvedi and Kumar (2015) mentioned that the nutritional status of apparel workers is generally poor, as a result of low pay and the poor quality of food provided in factory canteens. The authors further highlighted that the need to meet production targets forces workers to skip their lunch and small breaks. They often do not drink enough water in order to avoid going to the restroom. This predisposes them to Urinary Tract Infection (UTI). As per Ahmed and Raihan (2014), the income level of the female workers in the garment sector is very poor. The workers cannot buy even a balanced meal or fresh food to survive. Therefore, they always suffer from malnutrition, diarrhoea, dysentery, less appetite, food poisoning, pain in abdomen, and gastric pain.

\section{Research Methods}

Initially, a comprehensive literature survey was carried out in order to obtain the knowledge regarding $\mathrm{OSH}$ and $\mathrm{OSH}$ hazards. The referred data sources include published journal articles, conference proceedings, reports from government and nongovernment associations, articles from websites, etc. in the relevant field. The research adopted a quantitative approach and a detailed questionnaire survey was conducted to identify the level of exposure of employees to the identified $\mathrm{OSH}$ hazards in apparel manufacturing organisations.

\section{Sampling}

Sampling can be defined as the method of selecting a representative sample from a population (Tan, 2002). However, selecting most appropriate sample for the study is quite critical. The test sample was selected randomly from apparel manufacturing employees of Northern Province in Sri Lanka. This research study contains main groups of participants from apparel manufacturing employees of Northern Province, who have enough experience on apparel production procedures. To this research, nonprobability sampling method was adopted because at the beginning, exact sample size of the population was unknown. Hence, he questionnaire survey was carried out among 76 employees of randomly selected eight different apparel manufacturing organisations in Northern Province of Sri Lanka. 


\section{Measures of variables}

Data gathered through questionnaire survey and the detailed questionnaire contained a list of OSH hazards identified through the literature survey. A 1-5 Likert scale where 1 represented very low level of exposure and 5 represented very high level of exposure was used to identify the exposure levels to OSH hazards. The data analysis was done using RII (Relative Importance Index) method. Equation 1 shows the equation used to calculate RII values. Hence, the significant OSH hazards were identified based on calculated RII values values.

Where, $\mathrm{W}=$ constant expressing the weighting given to each response, $\mathrm{n}=$ the frequency of response, $\mathrm{A}=$ the highest weighting and $\mathrm{N}=$ total number in the responses, RII is as follows.

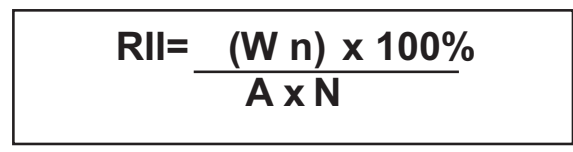

(Eq: 01)

Source: Johnson \& LeBreton (2004)

\section{Discussion and Analysis of Research Findings}

Apparel manufacturing employees of Northern Province were the respondents of the study and therefore, when selecting the respondents, their nature of work was specifically considered. i.e. it was conducted among employees who are involving in apparel manufacturing work. Hence, with the cost and time considerations, ninety-six (96) questionnaires were distributed among apparel manufacturing workers selected from eight (08) apparel manufacturing organisations. Among them, only seventysixquestionnaires were responded which symbolizes a response rate of $79.17 \%$. The respondents' details are summarised in Figure 1.

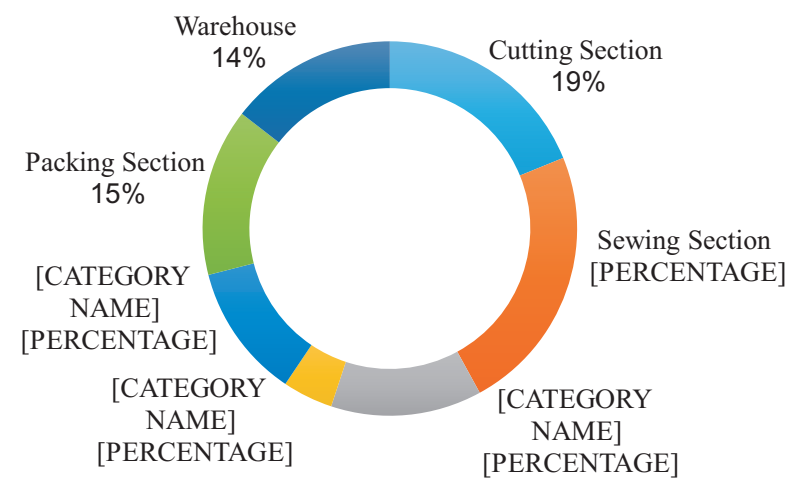

Figure 1 - Profile of Respondents 
The respondents were provided with a semi-structured questionnaire in which 31 number of OSH hazards were listed. They were required to mention their level of exposure to the all the listed OSH hazards. Based on their responses, the RII values were calculated. The calculated RII values were used as a tool to identify the significant hazards under each main hazard category. The following sections discuss the questionnaire survey findings of the research.

\section{Level of Exposure to Physical Hazards}

Generally, the apparel workers start their works on 8.30 a.m. and finish around 5 p.m. with one hour lunch break. Except the lunch break, employees are working on their work floor. The employees' exposure levels to physical hazards have been depicted in Figure 2. According to the respondents, "Excessive noise" was ranked first with a RII value of 0.901 among the nine identified physical hazards. Because, in sewing section, there are many sewing machines operate at once. Therefore, the noise is at a high level. The cutting section and other related sections are located nearby the sewing section. The people who are working in those sections are also affected by this noise. As the Figure 2 shows, "Untidy working environment" is the next significant hazard with the RII with the exposure level of 0.893 . Likewise, "Absence of health facilities" was ranked in third position holding RII value 0.867 , due to less facilities provisions for pure drinking water, washroom facilities and rest room facilities.

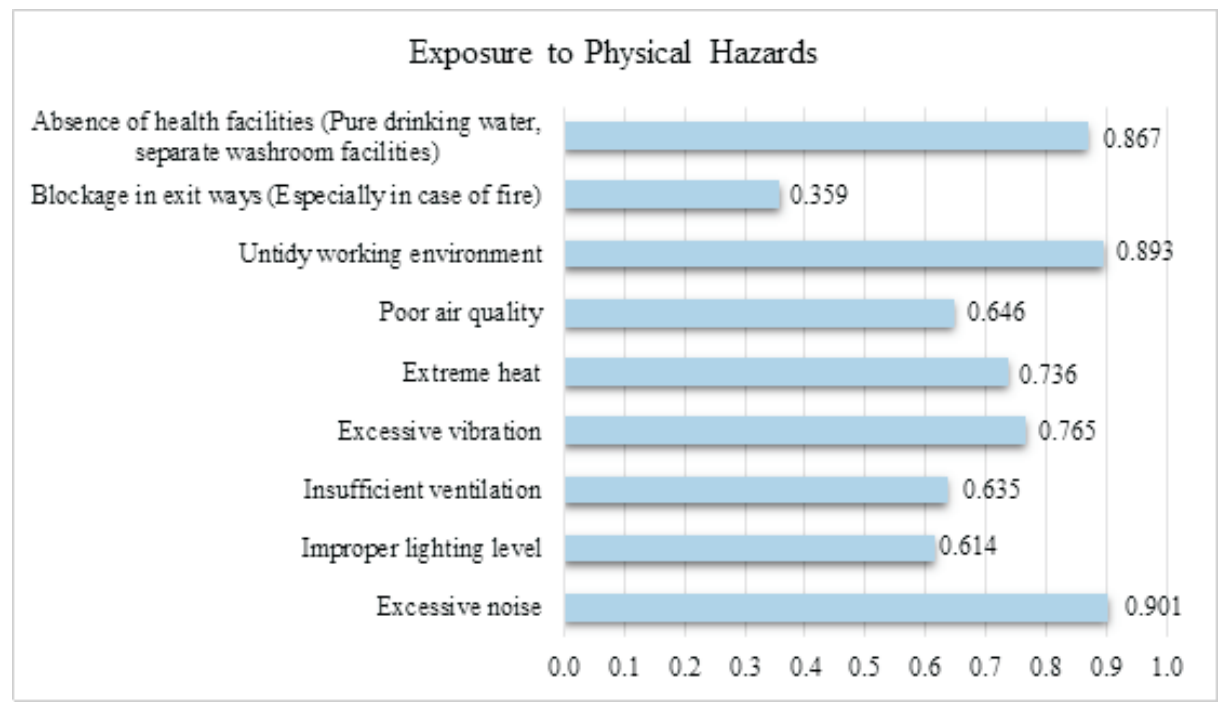

Figure 2: Level of exposure to physical hazards

"Extreme heat", "Excessive vibration" and "Poor air quality" are the hazards to which next the employees are exposed to respectively. "Insufficient ventilation" is ranked 
with 0.635 RII value. In the sewing sections, many assembly lines and large number of employees are working. Due to the crowd, proper ventilation is not there. In addition to that, "Improper lighting level" has been ranked with RII value of 0.614. However, sewing, cutting, quality control and button holding employees need to have a proper lighting level. Except the physical hazard, "Blockage in exit ways" $(\mathrm{RII}=0.359)$ all the other physical hazards have received RII value greater than 0.6 suggesting that all the other hazards are significant in the present context.

\section{Level of Exposure to Ergonomic Hazards}

The RII values related to ergonomic related hazards are shown in Figure 3. Majority of the respondents stated that "Repetitive nature of work" is the major hazard under ergonomic hazard with RII value of 0.986 . As per the findings "Awkward postures, "Poor ergonomic design of workstation and work condition", "Inadequate circulation spaces" and "Lack of shifting and rotation system" have also gained RII values greater than 0.9 showing that apparel manufacturing employees are highly exposed to those ergonomics related hazards (Refer Figure 3). In the cutting sections, distance between the tables are very narrow. Therefore, the people work in that section face difficulties to move around and to carry the fabric rolls and cutting materials. In the sewing sections, mostly there are two employees for one machine. If one employee sew, other employee will be the helper to collect the materials. Therefore, in sewing section there are lots of employees and available space is not adequate for circulation.

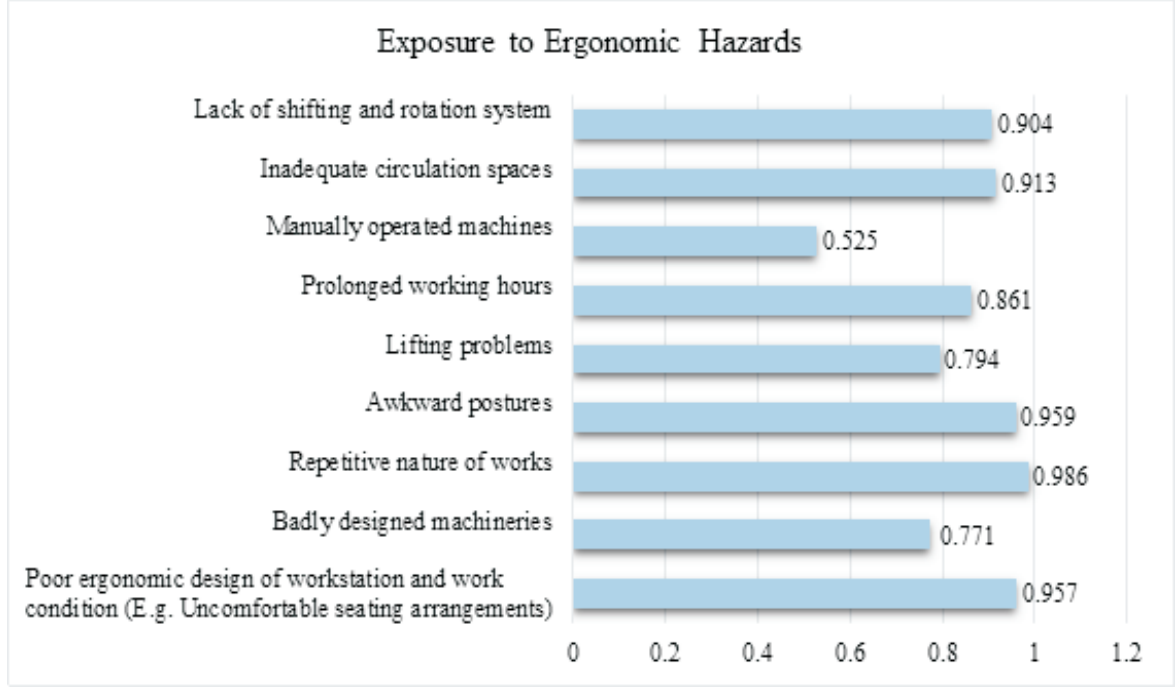

Figure 3: Level of exposure to ergonomic hazards 
The RII values received for "Prolonged working hours", Lifting problem" and "Badly designed machines" are $0.861,0.794$ and 0.771 respectively. Warehouse employees need to arrange the boxes in warehouse and therefore, they need to bend down and arrange in the tracks. In the cutting section, the employees need to lift the fabrics and put on the tables. And in the packing section, the employees have to walk between boxing areas and bagging bands, carry the products from the bands and bend down to place them to boxes. Hence, as the findings revealed, the employees who are working in warehouse, cutting and packing sections are greatly exposed to "Lifting problem". On the other hand, due to the non-adjustable machineries in sewing sections, sewing employees need to sit many hours on a hard tool with no support and also there are chances to the employees of cutting section to cut their hands in electric cutting machines. As per the findings, the employees are no greatly exposed to "Manually operated machines". Further, though automatic and motor driven machineries and tools are commonly used in sewing, cutting and ironing sections, generally quality control, washing, button holding, packing, warehouse sections are not much equipped with machinery.

\section{Level of Exposure to Psychological Hazards}

The Figure 4 shows the RII values received for psychological hazards. According to the respondents, "Stress" is the most significant psychological hazard holding the RII value of 0.922 . The main reasons for stress are repetitive movements, improper design of work stations, noisy environment and pressure to achieve the given targets

Exposure to Psychological Hazards

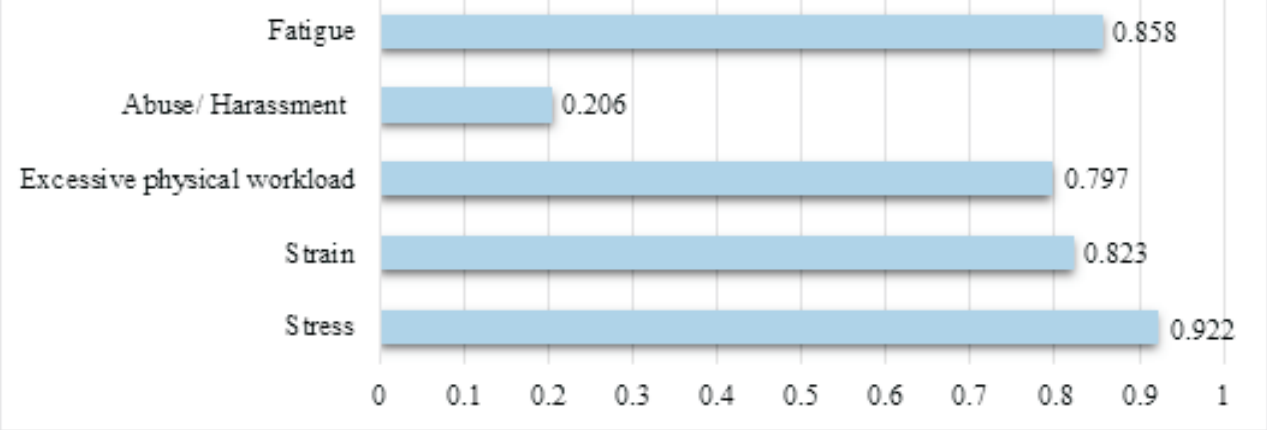

Figure 4: Level of exposure to psychological hazards

Moreover "Fatigue" (RII $=0.858)$ has also been stated as a main hazard coming under the psychological hazards. The works in sewing and cutting sections lead to increased fatigue due to continuous handling of loads, prolonged standing, repetitive movement of both hands and wrists and awkward postures. 
The employees working with manually handling equipment are also affected by fatigue. For an example, in the ironing section, employees standing for hours and pushing down on the iron will result in fatigue. Further, "Strain" and "Excessive workload" have received RII values of 0.823 and 0.797 respectively indicating that employees are largely exposed to those hazards. However, the RII value of the hazard "Harassment" is 0.206 and it shows that employees are less exposed to that hazard in the present scenario.

\section{Level of Exposure to Chemical Hazards}

As the findings revealed with a very high RII value, i.e. 0.910, "Excessive exposure to cotton dusts" is the most significant chemical hazard to which, the employees are exposed to (Refer Figure 5). Cotton dust is mainly generated from cutting and sewing activities of apparel organisations and can be spread all around the sections being a hazard for employees in those sections. Further, "Emissions of toxic substances from dye" has also gained a higher RII value i.e. 0.907. The employees of dyeing, printing, finishing and washing sections are greatly suffer from the emission of toxic substances from dye. "Inhaling dust from fabrics" holds the third main hazard which has the RII value of 0.878 . This shows that apparel organisations have failed to take effective actions to minimize the effects of fabrics exposures. However, "Exposure to dangerous chemicals" and "Inhaling dust from machines" have received RII values less than. 0.5 and it shows that the level of exposure to those chemical hazards is not that significant.

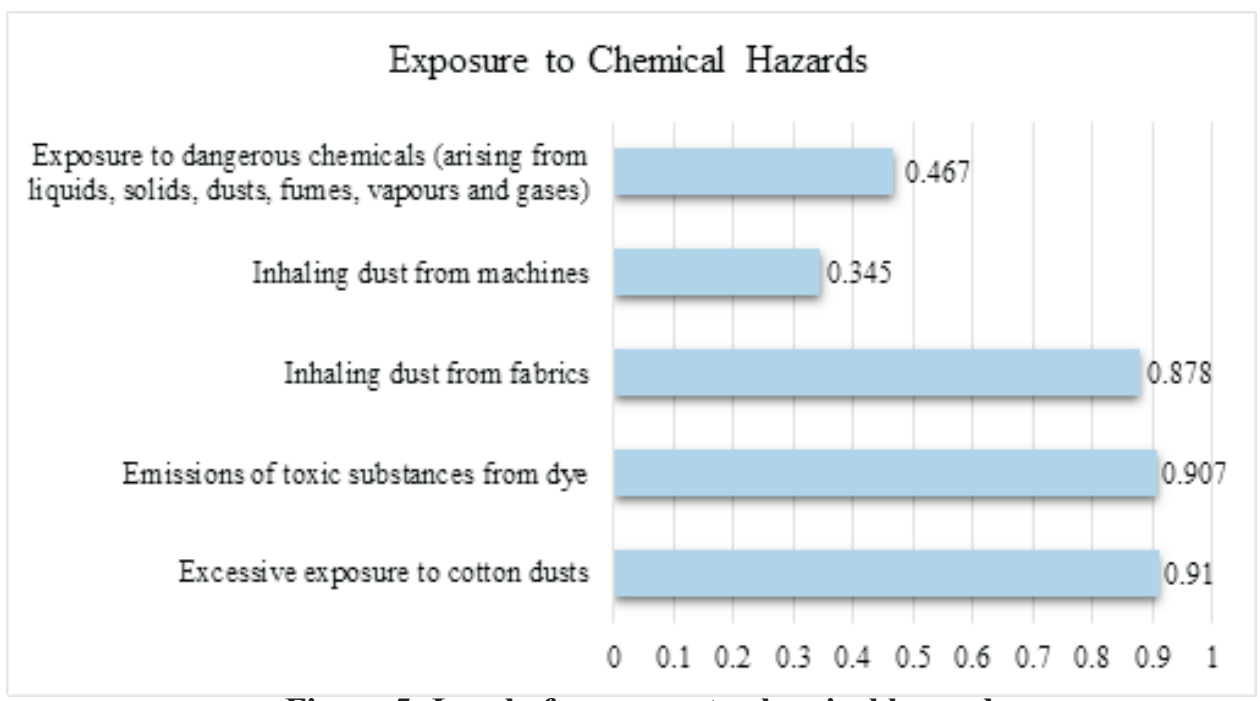

Figure 5: Level of exposure to chemical hazards 


\section{Level of Exposure to Biological Hazards}

Figure 6 shows the questionnaire survey findings related to the employees' exposure levels to biological hazards. As per the discussion with employees, it could be understood that the most of the employees are from the villages which are located far

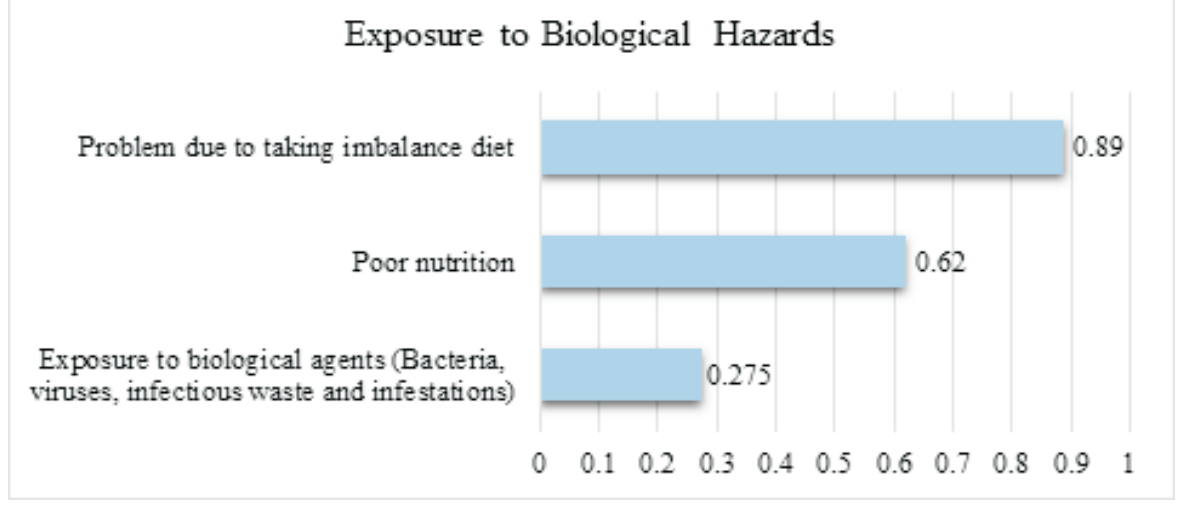

Figure 6: Level of exposure to biological hazards

away from the apparel organisations. They always try to come for the work sharply around $8.30 \mathrm{a} . \mathrm{m}$. and avoid their breakfast due to the rush time. Therefore, with the RII value of 0.8 "Problem due to taking imbalance diet" was ranked as hazard with most significant level of exposure. "Poor nutrition" leads the next significant biological hazards with the RII value of 0.62. Furthermore, "Exposure to biological agents" holds the RII value of 0.275 which indicated is insignificant.

4.6 Ranking of OSH Hazards of apparel Manufacturing organisations in Northern Province of Sri Lanka.

Finally, all the hazards identified through the literature (refer Table 1) based on exposure levels (RII values) of apparel manufacturing workers in Northern Province were ranked and presented in Table 2. "Repetitive nature of work" hazard was ranked as the hazard to which the employees are most extremely exposed in the current practice with RII value of 0.986 . Because, all the sections in apparel manufacturing process are exposed to this hazard. Most of the employees experience feelings of boredom because of the repetitive nature of the work. The work in the units are highly repetitive in nature, requiring a combination of both state and rhythmic muscular activity. When such works are repeated several times in a day, this leads to ill health of workers. "Awkward postures" $(\mathrm{RII}=0.959)$ as well as "Poor ergonomic design of workstation and work condition" ( $\mathrm{RII}=0.957)$, could also be identified as the hazards with extremely high level of exposure as they have gained RII values very close to 1 . 
The OSH hazards ranked number 4 to 20 have received RII values greater than or closer to 0.8 representing that they are the hazards to which employees are highly exposed to at present. Hence, the findings provide insights that those hazards should be given special attention as higher exposure levels have a higher probability to occur OSH hazards.

Table 2: Ranking of hazards based on RII

\begin{tabular}{|l|c|c|}
\hline \multicolumn{1}{|c|}{ Hazards } & RII & Overall Rank \\
\hline Repetitive nature of works & 0.986 & 1 \\
\hline Awkward postures & 0.959 & 2 \\
\hline Poor ergonomic design of workstation and work condition & 0.957 & 3 \\
\hline Stress & 0.922 & 4 \\
\hline Inadequate circulation spaces & 0.913 & 5 \\
\hline Excessive exposure to cotton dusts & 0.910 & 6 \\
\hline Emissions of toxic substances from dye & 0.907 & 7 \\
\hline Lack of shifting and rotation system & 0.904 & 8 \\
\hline Excessive noise & 0.901 & 9 \\
\hline Untidy working environment & 0.893 & 10 \\
\hline Problemdue to taking imbalance diet & 0.890 & 11 \\
\hline Inhaling dust from fabrics & 0.878 & 12 \\
\hline Absence of health facilities (Pure drinking water, separate washroom & 0.867 & 13 \\
\hline facilities) & & \\
\hline Prolonged working hours & 0.861 & 14 \\
\hline Fatigue & 0.858 & 15 \\
\hline Strain & 0.823 & 16 \\
\hline Excessive physical workload & 0.797 & 17 \\
\hline Lifting problems & 0.794 & 18 \\
\hline Badly designed machineries & 0.771 & 19 \\
\hline Excessive vibration & 0.765 & 20 \\
\hline Extreme heat & 0.736 & 21 \\
\hline Poor air quality & 0.646 & 22 \\
\hline Insufficient ventilation & 0.635 & 23 \\
\hline Poor nutrition & 0.620 & 24 \\
\hline Improper lighting level & 0.614 & 25 \\
\hline Manually operated machines & 0.525 & 26 \\
\hline Exposure to dangerous chemicals & 0.467 & 27 \\
\hline Blockage in exit ways (Especially in case of fire) & 0.359 & 28 \\
\hline Inhaling dust from machines & 0.345 & 29 \\
\hline $\begin{array}{l}\text { Exposure to biological agents (Bacteria, viruses, infectious waste and } \\
\text { infestations) }\end{array}$ & 0.275 & 30 \\
\hline Abuse/ Harassment & 0.206 & 31 \\
\hline & & \\
\hline
\end{tabular}


Moreover, as per the findings, the employees are averagely exposed to "Poor air uality", "Insufficient ventilation", "Poor nutrition", "Improper lighting level", "Manually operated machines", and "Dangerous chemicals". The "Blockage in exit ways", "Inhaling dust from machines"," "Exposure to biological agents"and "Abuse/ Harassment" have received RII values less than 0.4 suggesting that there is very low level of exposure to employees

\section{Conclusions and Recommendations}

This study attempted to identify the exposure levels of employees working in apparel manufacturing organisations in Northern Province of Sri Lanka to different OSH hazards. Further, it provides an insight to the various researches on OSH in apparel manufacturing industry. Most of the existing research findings concludes that $\mathrm{OSH}$ has become as a problem and that needs to be addressed both in developed and developing countries. The literature review identified that the OSH in apparel manufacturing industry in developing countries have not received adequate attention. Further, the literature findings revealed five types of major OSH hazards, i.e. physical, ergonomic related, psychological, chemical and biological.

Hence, this study addressed OSH hazards under those five categories and the RII values represent the exposure levels to different OSH hazards. The questionnaire survey results showed that, out of the 31 hazards identified through the literature review (Refer Table 1), level of exposure of the employees to ergonomic hazards are at a significant level. There are few studies on OSH hazards faced by apparel workers in Asian countries which show that, workers face major problems from sitting and standing for long periods of time, chemical exposure, dust, broken needles and physical accidents. European Agency for Safety and Health at Work stated that the apparel sector in Europe contains many hazards and risks to workers, ranging from exposure to noise and dangerous substances, to manual handling and working with dangerous machinery. Each processing stage from the production of materials to the manufacturing, finishing, colouring and packaging poses risks for workers and some of these are particularly dangerous for employees' health. Hence, the findings of this study also complies with the researches done in Asian and Western countries as well.

As this study showed, OSH hazard can be extremely harmful to the humans' safety and health. Therefore, a careful attention should be given to minimise the exposure levels to those hazards and take necessary actions to avoid and minimize the OSH issues that can be caused because of OSH hazards. The hazard identification and assessment 
(OSH risk assessment), hazard prevention and control and provision of education and training to employees can be recommended to the practitioners in this area to overcome the OSH hazards and effectively handle them. Further, systematic planning and execution of OSH management within an organisation should be initiated by the top management of the organisations. The implementation of management practices such as OHSAS 18001, Occupational Health and Safety Assessment Series will also strengthen the organisations' efforts to achieve effective OSH management within an organisation.

\section{Further Research Directions}

This research identified the significant OSH hazards of apparel manufacturing organisations in Nothern Province of Sri Lanka. This study can be further extended to investigate the current OSH management practices and come up with strategies to improve them in the same context. Further, the paper encourages an agenda for future research that advocates an investigation of OSH hazards and evaluation of the critical exposure levels of those hazards in different organisations in different sectors, in the national and international contexts.

\section{References}

Ahmed, S., \& Raihan, M. Z. (2014). Health status of the female workers in the garment sector of Bangladesh. Journal of The Faculty of Economics and Administrative Science, 4(1), 43-58.

Alli,B. O. (2008). Principles of Occupational Health and Safety. Geneva: International Labour Organisation.

Amponash, T., \& Dartey, B. (2011). Occupational Health and Safety: Key Issues and Concerns in Ghana. International Journal of Business and Social Science, 14(2), 120-126.

Athit, K. (2005). Hazards in Combodian Garment Factories. Occupational Sfety and Health.

Bhagawati, B. (2015). Basics of Occupational Safety and Health. IOSR Journal of Environmental Science, Toxicology and Food Technology, 9(8), 91-94. doi:10.9790/2402-09819194 
Bheda, R. (2004). Improving working condition and Productivity in the Garment Industry. New Delhi.

Chaturvedi, L. C., \& Kumar, A. (2015). A Study of Occupational Health and Safety in the Garment Industry in Bangalore. Retrieved March 26, 2018, from http:/cividep.org/wp-content/uploads/2017/04/25-2-Occupational-healthsafety-13.pdf

De Silva, N., \& Wimalaratne, P. (2012). OSH management framework for workers at construction sites in Sri Lanka. Engineering, Construction and Architectural Management, 19(4),369-392. doi:10.1108/09699981211237094

Drusilla, K. B., Deardorff, A. V., \& Stern, R. M. (2011). Labor Standards and Human Rights: Implications for International Trade and Investment. University of Michigan.

Eddie , W. L., \& Fang, D. P. (2004). Construction safety management. journal of construction, 4(2), 229-241.

European Agency for Safety and Health at Work. (2012). Management of occupational safety and health. Analysis of the findings of the European Survey of Enterprises on New and Emerging Risks (ESENER). Retrieved March 26, 2018, from https:/osha.europa.eu/ en/ tools-and-publications/ publications/ reports/management-of-occupational-safety-and-health-analysis-of-datafrom-the-esener

European Agency fro Safety and Health at Work. (2005). Priorities for occupational safety and health research in the EU-25. Retrieved March 28, 2018, from https://osha.europa.eu/en/tools-and-publications/publications/reports/6805648

Industrial Accident Prevention Association. (2007). Glossary of Occupational Health \& Safety Terms. Retrieved March 25, 2018, from http://www.iapa.ca/ pdf/ iapa_glossary.pdf

International Labour Organisation. (2010). Emerging risks and new patterns of prevention in a changing world of work. Retrieved March 26, 2018, from http://www.ilo.org/public/portugue/region/eurpro/lisbon/pdf/28abril_10_en.pdf

International Labour Organisation. (2014). Safety and Health at Work. Geneva: ILO. 
International Labout Organisation. (2001). Guidelines on occupational safety and health management system. Retrieved March 26, 2018, from http://www.ilo.org/wcmsp5/groups/public/@ed_protect/@protrav/@safework /documents/normativeinstrument/wcms_107727.pdf

Jana, P. (2008). Ergonomics in Apparel Manufacturing: Importance and Impact of Ergonomics. Stitch World, 6(1), 42-47.

Johnson, J. W., \& LeBreton, J. M. (2004). History and Use of Relative Importance Indices in Organizational Research. Organisationsal Research Methods, 7, 238257. doi:10.1177/1094428104266510

Khan, N. R., Dipti, T. R., Ferdousi, S. K., Hossain, M. Z., Ferdousi, S., Sony, S. A., \& Islam, M. S. (2016). Occupational Health Hazards Among Workers of Garment Factories in Dhaka City, Bangladesh. Journal of Dhaka Medical College, 24(1), 36-43.

Koruca, H. I. (2011). Evaluation of Working Life Quality For A Textile Company in Turkey: A Case Study. Gazi University Journal of Science, 24(1), 101-112.

Laville, A. (1985). Postural stress in high-speed precision work. Journal of Ergonomics, 28(1), 229-236.

Legesse, M. (2016). Impact of Occupational Safety and Health on Organizational Performance in East Africa Bottling Sh. Co.East Africa: Addis Ababa University.Retrievedfrom http://etd.aau.edu.et / bitstream/ 123456789/ 12143/1/Muluken\%20Legesse.pdf

Lu, J. L. (2011). Occupational health and safety of women workers: Viewd in the light of labour regulation. Journal of International Women's Studies, 12(1), 68-78.

Mahmud, M. S., Mahmud, R., Jahan, M. N., Hasan, M. R., \& Rahman, K. M. (2017). Prevalence of Health Hazards: A Study on the Female Workers of Garment Industry in Gazipur District, Bangladesh. Journal of Applied and Advanced Research, 2(3), 184-188.

Mehta, R. (2012). Major Health Risk Factors prevailing in Garment Manufacturing Units of Jaipur. Journal of Ergonomics, 2(2), 102. doi:10.4172/21657556.1000102

Mohibullah, A. T., Takebira, U. M., Moni, K. N., \& Rahman, M. (2018). Social Compliance, Occupational Health and Environmental Safety Management 
Practice in the Apparel Industry of Bangladesh: An Overview. Mohibullah ATM, Takebira UM, Moni KN, Rahman M (2018) Social Compliance, Occupational Health and Environmental Safety Management Practice in the Apparel Industry of Bangladesh: An Overview. Journal of Textile Science Engineering, 342. doi:10.4172/2165-8064.1000342

Motbainor, A., Kumie, A., \& Melkamu, Y. (2007). Assessment of knowledge and practice on safety information among factory workers. Ethiopia: Addis Ababa University. Retrieved from http://etd.aau.edu.et/bitstream/123456789/3059/ 2/Microsoft $\% 20$ Word\%20-\%20final.pdf

Occupational Safety and Health Council. (2003). Biological Hazards: Prevention and Personal Protection, A practical guide especially for frontline workers. Retrieved from http://www.oshc.org.hk/oshc_data/files/HotTopic/CB959E.pdf

Polat, O., \& Kalayci, C. B. (2016). Ergonomic Risk Assessment of Workers in Garment Industry. Eight International Conference on Textile Science \& Economy VIII, (pp. 16-21). Zrenjanin, Serbia.

Salvai, P. (2015). Building a culture of Occupational Safety and Health in the Ready Made Garment sector: analysis of the project model and main achievements. International Labour Organisation. Retrieved March 28, 2018, from https://www.itcilo.org/en/the-centre/programmes/employersactivities/osh/building-a-culture-of-occupational-safety-and-health-in-theready-made-garment-sector-analysis-of-the-project-model-and-mainachievements

Saravanan, K. (2011). Importance and need of ergonomics in the apparel industry. Pakistan Textile Journal, 60(1).

Sealetsa, O. J., \& Thatcher, A. (2011). Ergonomics issues among sewing machine operators in the textile manufactring industry in Botswana. Work, 38(3), 279289. doi:10.3233/WOR-2011-1131

Sharif, P. A., Islam, M. E., \& Kabir, R. A. (2015). A Study on Occupational Health \& Safety Practices in RMG Factories of Bangladesh in Accordance with Compliance after Rana Plaza Incident. The International Journal of Business \& Management, 3(5), 214. 
Sobuj, M. R. (2011). Safety problems of garments worker and prevention. doi:10.13140/RG.2.1.3753.8722

Talapatra, S., \& Rahman, M. H. (2016). Safety Awareness and Worker's Health Hazards in the Garments Sector of Bangladesh. European Journal of Advances in Engineering and Technology, 3(9), 44-49.

Tawiah, K. A., \& Mensah, J. (2016). Occupational Health \& Safety and Organizational Commitment: Evidence from Ghanaian Mining Industry. Safety and Health at Work, 7(3), 225-230. doi:10.1016/j.shaw.2016.01.002

World Health Organisation. (1995). Global Strategy on Occupational Health for All: The Way to Health at Work. Beijing. Retrieved March 25, 2018, from WHO, 1995, Global Strategy on Occupational Health for Allhttp://www.who.int/ occupational_health/publications/globstrategy/en/

World Health Organisation. (2001). Occupational Health: A Manual for primary health care workers. Retrieved March 27,2018,from http://www.who.int/ occupational_health/regions/en/oehemhealthcareworkers.pdf 